\title{
O urbano em questão na antropologia: interfaces com a sociologia ${ }^{1}$
}

\author{
Heitor Frúgoli Jr. \\ Professor do Departamento de Antropologia - USP
}

RESUMO: O artigo aborda temas em torno da dimensão urbana na antropologia, explorando diálogos de fronteira entre tal disciplina e a sociologia em três momentos específicos: o primeiro sobre as décadas iniciais da Escola de Chicago, época de definição de uma pauta de pesquisas etnográficas sobre a cidade e a cultura urbana, com investigações pioneiras sobre a segregação socioespacial, com ênfase no conceito de gueto; no segundo, analisam-se interfaces entre a antropologia e a sociologia urbanas em São Paulo, nas décadas de 1970 e 1980, em torno do tema da periferia, com a produção de pesquisas marcadas pela polarização entre os conceitos de cultura e ideologia; finalmente, enfocam-se desafios contemporâneos à antropologia urbana, buscando-se retomar tópicos de um diálogo disciplinar que ocorre apenas implicitamente, bem como reaver o tema da periferia, tendo em vista fenômenos recentes que implicam tomá-la simultaneamente como espacialidade, processo e conjunto polifônico de representaçôes nativas.

PALAVRAS-CHAVE: antropologia urbana, sociologia urbana, diálogos de fronteira, segregação socioespacial. 
Heitor Frúgoli Jr. O urbano em questão na antropologia...

\section{Teoria e etnografia na Escola de Chicago: relações entre sociologia e antropologia}

Dentre os objetivos do presente artigo, o principal é articular reflexões sobre as especificidades da dimensão urbana na antropologia, dialogando com uma certa tradição nesse campo, na direção de uma pretendida antropologia $d a$ cidade, e não apenas na cidade. ${ }^{2}$ Nesse sentido, refirome principalmente às abordagens que tomam a cidade ou o contexto urbano como tema substancial da reflexão, não bastando, portanto, que apenas digam respeito a quaisquer fenômenos que ocorram dentro da esfera urbana. ${ }^{3}$

Parte da formação e de certos desdobramentos do campo da antropologia urbana pode ser compreendida mais claramente, de meu ponto de vista, por meio de aproximações, afastamentos e diferenciações com a sociologia urbana, tendo em vista o diálogo estabelecido entre essas duas perspectivas a partir da Escola de Chicago, a primeira a tomar a cidade como "laboratório privilegiado de análise da mudança social" e a formular uma "concepção 'espacializada' do social e, reciprocamente, socializada do espaço" (Cuin \& Gresle, 1994, p. 191 e 193). ${ }^{4}$ Evidentemente que a menção a essa Escola implica uma retomada crítica de seus fundamentos - fato recente assinalável num certo âmbito do contexto acadêmico francês ${ }^{6}$-, à busca de compreensão da mesma enquanto uma espécie de ponto de convergência e de influência mútua entre duas vertentes disciplinares, ainda que depois tenha ocasionado uma espécie de "divisor de águas" entre elas, como logo veremos.

Antes de prosseguirmos, brevíssimas consideraçoes sobre a delimitação de fronteiras disciplinares: não se está propondo aqui uma interdisciplinaridade ou "transdisciplinaridade" entre antropologia e sociologia, mas uma perspectiva disciplinar, ou seja, um eixo de análise (no caso antropológico) com objetos e métodos próprios que incorpo- 
ra, numa perspectiva hierárquica, outros campos de saber. A presente perspectiva vai assim nessa direção, mesmo considerando que as fronteiras em geral sejam marcadas por campos de diálogo e intersecção ora proveitosos, através de várias mediações - como nas interfaces entre antropologia e história, amplamente debatidas entre nós ${ }^{7}-$, ora bastante ásperos - se pensarmos, por outro lado, nas relações entre antropologia e psicanálise, já chamadas de "diálogo de surdos" ou "guerra intertribal" (cf. Musumeci, 1991, p. 219). O campo suficientemente vasto das interfaces entre antropologia e sociologia - no caso duas vertentes do interior das ciências sociais -, por sua vez, iria nos levar a inúmeras considerações que não é possível aprofundar aqui, ${ }^{8}$ cabendo tentar reconstituir, numa circunscrição mais precisa, partes significativas dos diálogos entre a antropologia e a sociologia urbanas.

Comenta-se às vezes que as perspectivas antropológica e sociológica sobre as cidades seriam parecidas, pelo fato de enfocarem objetos ou fenômenos a princípio idênticos. Pode-se discordar tendo em vista o fato de que muitas vezes os objetos são distintos, mas, mesmo quando há uma convergência de enfoques, tal impressão de semelhança se dissipa na medida em que se atenta à tradição de abordagem de cada uma delas, sobretudo quanto às sínteses particulares da relação entre teoria e pesquisa ou, mais especificamente, à forma de incorporar os impactos da pesquisa - sobretudo a etnográfica ${ }^{9}$ - na própria construção teórica. Sem tentar, portanto, uma separação "à força” entre as duas disciplinas, podese confrontá-las quanto ao olhar e à reflexão de ambas sobre a cidade no tema mencionado. Isso estaria presente, inclusive, na gênese da diferenciação entre sociologia e antropologia na Escola [sociológica] de Chicago, em que há consenso que os enfoques iniciais sobre a cultura urbana e as práticas etnográficas em contextos urbanos, dois temas importantes para a antropologia, foram gerados. Naquele contexto, diversas pesquisas etnográficas sobre a cidade foram inicialmente conduzidas por soció- 
Heitor Frúgoli Jr. O urbano em questão na antropologia...

logos, cujos achados empíricos muitas vezes colocavam em xeque várias premissas e hipóteses, sem que o cabedal teórico fosse suficientemente revisto, numa tensão que veio a ser melhor equacionada posteriormente, no interior de uma antropologia urbana propriamente dita. ${ }^{10}$

Em linhas gerais, a noção de cultura urbana formulada pela Escola de Chicago, fruto de um conjunto amplo de pesquisas, pode ser creditada principalmente a três autores: Park (1987[1916]), que concebeu a cidade como um campo de investigaçôes da vida social, influenciando várias pesquisas da época (Becker, 1996), bem como, numa segunda etapa, os contrapontos entre os estudos de Wirth (1987[1938]), que culminaram no conceito de urbanismo enquanto modo de vida - com base em variáveis como tamanho, densidade e heterogeneidade -, e de Redfield (1974 [1930] e 1947), assentados em pequenas localidades que originou os "estudos de comunidade" -, cujo desenvolvimento levaria presumidamente a processos de urbanização, sintetizados no conceito de continuum folk-urbano (Hannerz, 1980). ${ }^{11}$

Tal noção era inspirada em autores clássicos da sociologia da passagem do século XIX para o XX, como Durkheim, Weber, Tönnies e Simmel, todos voltados, por caminhos distintos, à compreensão das especificidades das sociedades modernas, cujo pano de fundo privilegiado foram as metrópoles industriais, com intensas mudanças no plano urbanístico, populacional (dado um novo ciclo de desenraizamento rural) e nos modos de vida, o que inspirou mais diretamente alguns autores, como Simmel, que produziu vários escritos baseados em sua experiência como cidadão e transeunte da Berlim da época (Waizbort, 2000, p. 311-40). Em face a tal contexto, o autor assinalou a configuração do anonimato e da impessoalização, sendo o contato cotidiano entre estranhos nos espaços públicos marcado pela combinação entre proximidade física e distância social - ambigüidade, para o autor, constitutiva do moderno $^{12}-$, ocasionando a criação de estilos de vida caracterizados pela 
personalidade blasé - marcada por atitudes de reserva perante um mundo hostil, objetivado e em rápida mudança - bem como pelas relações de sociabilidade - formas lúdicas e recíprocas de associação e interação, sem qualquer caráter instrumental (Simmel, 1987[1902] e 1983[1917]).

Além de Simmel, desses autores derivou uma concepção de cultura urbana - que tratava a cidade como uma "variável independente" - assentada em distintas versóes da polaridade tradicional/moderno, como solidariedade mecânica/orgânica (Durkheim), tradicional/racional (Weber) e comunidade/sociedade (Tönnies) (Viveiros de Castro, 2002 [1996], p. 307), que seria sintetizada a priori nas seguintes características: "predominância dos papéis secundários [formalizados, contratuais ou institucionais] sobre os primários, isolamento, superficialidade, anonimato, relações sociais transitórias e com fins instrumentais, inexistência de um controle social direto, diversidade e fugacidade dos envolvimentos sociais, afrouxamento dos laços familiais e competição individualista" (Oliven, 1985, p. 14). ${ }^{13}$

Tais referências teóricas eram também marcadas, secundariamente, por uma ideologia de intervenção "pragmática" nos chamados "problemas urbanos", na busca de orientação ou respaldo científicos à implementação de políticas públicas nessa direção, sem falar dos programas incentivados por poderosas fundações filantrópicas (Hannerz, 1980; Stocking Jr., 2004). Tais "problemas", ou marcas de uma "desorganização social", teriam também uma determinada territorialidade específica, dentro da já citada concepção espacializada do social, norteada por uma "concepção ecológica" da estrutura urbana. ${ }^{14}$

A partir desse quadro, essa escola levou à frente uma prática pioneira de pesquisas etnográficas em campos como os da marginalidade, segregação étnica, criminalidade, prostituição, delinqüência e das várias formas de interação nos espaços públicos, sendo que muitos estudos mostravam também haver uma "organização" ou "ordenação" internas a esses locais 
Heitor Frúgoli Jr. O urbano em questão na antropologia...

ou fenômenos, o que ajudou aos poucos a sublinhar a diversidade constitutiva do contexto urbano. ${ }^{15}$ Sem nos alongarmos em detalhes, Hannerz (1980) mostrou como pesquisas sobre andarilhos, ${ }^{16}$ como a de Anderson (1961[1923]), que aos milhares passavam ou se fixavam temporariamente em Chicago, revelaram que muitos podiam se alternar em atividades como trabalhos sazonais do campo, empregos temporários em atividades informais urbanas e mendicância intercalada com pequenos furtos ou vadiagem; vários assumiam distintas identidades ao longo do tempo, incluindo vocabulários e discursos específicos a depender do contexto situacional, ${ }^{17}$ num estudo que lançou as bases para um "etnonomadismo" (Hannerz, 1980, p. 43). Isso pôde também se evidenciar em etnografias como a de Wirth (1956[1928]) sobre o tema do gueto, que, ao analisar o modo como judeus se congregavam em Chicago, tomou como contraponto histórico certos guetos judeus da Europa do Leste, procurando compreender a formação de um ethos comunitário entre eles, com uma vida social regular embasada na condição conterrânea, no uso do iídiche como idioma comum, em redes de ajuda mútua e nas práticas religiosas, enfatizando uma certa homogeneidade interna que se contrapunha à hipótese da "desorganização" - mesmo que posteriormente tal enfoque tenha se mostrado mais apropriado ao tema do enclave étnico, algo distinto das áreas urbanas marginalizadas habitadas involuntariamente por negros, vistas aí sim como guetos, com a redefinição de certas perspectivas de análise (Hannerz, 1980, p. 40-44). ${ }^{18}$ No campo de estudos sobre gangues, cabe citar o trabalho pioneiro de Thrasher (1963[1927]), dentro do pressuposto inicial de que seriam pequenos grupos situados em "interstícios urbanos”, típicos de áreas de desorganização social, mas cuja investigação veio a revelar formas de organização, com certas regras de relação em meio a um contexto extremamente vulnerável, articuladas a dinâmicas societárias do próprio bairro (Hannerz, 1980, p. 35-40). Essa small-groups dynamics ${ }^{19}$ inspirou 
trabalhos como o clássico Street Corner Society, de Whyte (1943), sobre um bairro pobre italiano de Boston, que configurou e comparou distintas tipologias de grupos jovens locais, divididos basicamente entre os "corner boys", mais voltados a atividades centradas na comunidade local, incluindo a possibilidade de participação em grupos mafiosos, e os "college boys", mais engajados num modelo competitivo de projeto de ascensão social e de saída do próprio bairro. ${ }^{20}$

Assim, é clara a importância que tal escola teve em investigações etnográficas que aos poucos permitiram estabelecer uma diferença entre diversidade e desorganização, abrindo espaço para uma série de investigaçôes antropológicas, que conferiram um outro estatuto à etnografia, algo que se consolidou sobretudo com os trabalhos de Lewis (1951 e 1976[1965]), em contraposição às já mencionadas abordagens de Redfield. ${ }^{21}$ Nesse sentido, as referências apriorísticas que circunscreviam a chamada cultura urbana foram uma a uma relativizadas (não propriamente negadas), estabelecendo-se um novo campo de referências para reflexão e pesquisa.

\section{Periferia paulistana na passagem dos anos 70 para os 80 : novos contrapontos entre antropologia e sociologia}

Tendo em vista as sínteses particulares do diálogo entre antropologia e sociologia urbanas até aqui reconstituídas, é oportuno passarmos para um outro período de contrapontos densos, quando dos enfoques e das pesquisas em torno da periferia de São Paulo entre o final da década de 1970 e a seguinte, com ênfase, portanto, num certo campo de interlocuções entre ambas no contexto paulistano. ${ }^{22}$

Pode-se dizer que, além de representar um fenômeno sociocultural e político relevante, a periferia despertou um significativo interesse nesse 
Heitor Frúgoli Jr. O urbano em questão na antropologia...

período por uma confluência de fatores que guardam relação com os contextos disciplinares até aqui abordados. No campo da sociologia, temos um quadro distinto do anterior: vários autores da sociologia urbana marxista que se desenvolveu na França, ${ }^{23}$ configurada dos anos 60 em diante, criticavam o culturalismo da Escola de Chicago, ${ }^{24}$ além da ausência de reflexões mais claras sobre dimensões determinantes no plano da economia e da política, tratando assim a cidade como "variável dependente". Havia desse modo uma busca de explicaçóes "macroestruturais", tendo como principal referência inicial o marxismo estruturalista, assinalado por uma "estrutura sem sujeitos" - numa outra síntese de fronteira entre marxismo e estruturalismo, operada por Althusser (1974) -, em que a cidade estaria basicamente subordinada ao processo de reprodução da força de trabalho. A emergência posterior de um conjunto de movimentos sociais por moradia e equipamentos urbanos coletivos, entretanto, ensejou uma gradativa relativização de tal "estrutura sem sujeitos", vindo a reforçar uma inseparabilidade entre o urbano e a política, e que se traduziu, no plano teórico, por uma forte aproximação entre tal sociologia urbana e a ciência política. ${ }^{25}$

Tais movimentos sociais ocorreram com particular proeminência nas áreas periféricas de grandes cidades latino-americanas, como São Paulo, local do surgimento de vários movimentos sociais urbanos, enfocados por autores como Kowarick (2000) - sobretudo através do conceito de espoliação urbana (1979) -, sem falar das experiências de reflexão e principalmente de intervenção no campo de um urbanismo que dialogava com o marxismo e a dimensão política. ${ }^{26}$

Nessa época já se praticavam, no Rio de Janeiro e em São Paulo, linhas de antropologia urbana que buscavam articular um campo autônomo de reflexão e pesquisa, embora com pequenas diferenciações internas. ${ }^{27}$ Numa espécie de balanço de tal produção no final dos anos 70 , Velho e Viveiros de Castro (1978) sublinhavam a necessidade da com- 
preensão das chamadas "sociedades complexas" - conceito hoje revisto e criticado (Goldman, 1999[1995]) -, através da compreensão de uma variedade de atores sociais da cidade - tendo em vista indivíduos que podem desempenhar distintos papéis sociais -, marcada por forte divisão social do trabalho, redes e instituições diversificadas e múltiplos focos de produção simbólica. Em tal artigo, já se apontava a necessidade de uma diferenciação entre cultura (conceito distintivo da antropologia) e ideologia (referente, na tradição marxista, a aspectos de dominação política derivada de conflitos de classe), tendo a primeira uma dimensão mais ampla, embora menos precisa, que a segunda. $\mathrm{O}$ desafio do enfrentamento dessa polaridade voltaria à tona com nova intensidade anos depois, como veremos a seguir.

No campo da antropologia urbana paulistana, várias pesquisas de fôlego desse período - como as de Macedo (1979), Magnani (1984) e Caldeira $(1984)^{28}$ - tomaram as áreas periféricas como local de pesquisa, buscando compreender detidamente redes de parentesco e de vizinhança, modos de vida, estratégias de sobrevivência, formas de sociabilidade e representações políticas, com ênfase em dimensóes cotidianas e em representações simbólicas, muito pouco contempladas nas perspectivas "macroestruturais". Tratava-se de um outro tipo de olhar sobre a periferia, alvo na época, como já dito, de interesses e enfoques diferenciados nas ciências sociais. Certos dados, num diálogo mais direto com a sociologia, mostravam como em várias representações nativas tal periferia era vista como um "processo", voltado à busca de "melhoria de vida" (Durham, 2004[1986b], p. 388-91), visível por meio das estratégias de longo prazo em torno da autoconstrução da casa própria, o que envolvia o desenvolvimento de certas redes, bem como em muitos casos a criação de uma "comunidade política" voltada à luta pela obtenção de equipamentos urbanos coletivos frente ao Estado. Entretanto, na ótica de tais pesquisas, a periferia revelava-se não apenas um lugar urbano específico 
Heitor Frúgoli Jr. O urbano em questão na antropologia...

marcado pela distância das áreas mais centrais, pela pobreza e pela carência de equipamentos coletivos, mas também um local de prática de formas peculiares de relações de sociabilidade, modos de consumo e lazer, bem como de representações da política (Durham, 2004[1986b], p. 379-80). Tais fenômenos a abordagem marxista não podia elucidar, dadas as diferenças e distâncias irredutíveis entre cultura e ideologia, uma vez que a primeira envolveria sistemas simbólicos (absorvidos e recriados nas práticas sociais) marcados por múltiplas determinações. ${ }^{29}$

O crescimento desses estudos, entretanto, suscitou novas reflexóes quanto a seu escopo e alcance. Tais temas foram abordados num balanço crítico de Durham em meados dos anos 80 (2004[1986a]), que, analisando a fértil produção da antropologia urbana da época, apontava que parte de tal visibilidade se devia ao fato de que os grupos pesquisados, em geral marginalizados, vinham ocupando um novo espaço na arena política, o que por isso mesmo trazia novos desafios para a própria prática antropológica, sobretudo quanto à relação entre sujeito e objeto. Se na sociologia ocorrera um abandono do funcionalismo positivista em virtude de uma crescente adesão da disciplina ao marxismo, resultando na não-elucidação de fenômenos "microssociais" (como vimos, de importância considerável), na antropologia, por sua vez, a crítica ao mesmo funcionalismo não ocasionou a delimitação de um novo campo metodológico comum, o que vinha levando, em vários casos de análises de grupos em processo de ampliação da cidadania, ${ }^{30}$ à ocorrência de "deslizes semânticos", ligados a uma politização na prática do campo (algo que por vezes resvalava, em termos malinowiskianos, a uma problemática "participação observante") concomitante a uma despolitização (talvez descontextualização seja mais apropriado) dos conceitos analíticos ou interpretativos, o que em suma exigia construções teóricas mais adequadas aos problemas enfrentados. ${ }^{31}$ 
As questôes enfrentadas nesse período, que ainda ecoam de forma significativa, abrem-se para a realidade mais recente, cujas indagações passam pelo enfrentamento de fenômenos relevantes em curso no contexto urbano, bem como os desafios para a antropologia urbana, no momento de uma relativa ausência de diálogos críticos com a sociologia, que abordarei na parte final deste artigo. ${ }^{32}$

\section{Desafios mais recentes para a antropologia urbana: breves apontamentos}

Dado que estamos num período relativamente próximo do anteriormente enfocado, e tendo em vista certos desdobramentos de fenômenos abordados, pode-se dizer que o tema da periferia - não apenas como espacialidade específica de segregação social, mas também como processo, inscrito num campo diversificado de representaçóes nativas - continua a constituir um significativo desafio contemporâneo para abordagens antropológicas, sobretudo no caso paulistano, além de sínteses diversas que possa adquirir em contextos distintos, ${ }^{33}$ sem descartar evidentemente outros temas ou espacialidades relevantes. ${ }^{34}$ Isso, contudo, exige avanços na compreensão do que se modificou e do que permaneceu do ponto de vista contextual, bem como conceitual, o que envolve - não exclusivamente, mas tendo em vista os temas aqui tratados - novos possíveis diálogos com outras áreas, assim como avanços no aprofundamento das possibilidades etnográficas.

Sem pretender definir um campo mais abrangente de abordagens possíveis, e tendo em vista as sendas já abertas neste artigo, pretende-se explorar aqui novas potencialidades com respeito ao tema da periferia, incorporando enfoques mais recentes. Várias análises têm apontado que 
Heitor Frúgoli Jr. O urbano em questão na antropologia...

é mais apropriado falar em periferias - no plural -, embora de um certo modo isso já fosse uma ênfase da antropologia urbana nos anos 80. Cabe então entender que a pluralidade da qual agora está se falando diz respeito, em termos territoriais, aos diversos graus de consolidação desses bairros ou dessas localidades quanto aos equipamentos coletivos urbanos disponíveis (Caldeira, 2000, p. 235-41; Marques \& Bichir, 2001), embora boa parte dos mesmos continue marcada por inúmeras precariedades (Kowarick, 2004, p. 62-64). Tal quadro mais heterogêneo seria resultante, em vários casos, da própria luta de moradores organizados pela melhoria do bairro ou dos atendimentos diferenciados de tais demandas por parte do Estado, embora o efeito perverso, em várias situações, venha sendo a expulsão de parcelas de moradores mais pobres dessas áreas, em face dos efeitos e custos decorrentes da própria consolidação. ${ }^{35} \mathrm{O}$ crescente desemprego, aliado à sensível diminuição do ritmo migratório, por sua vez, tem relativizado o chamado padrão periférico de crescimento urbano de São Paulo, com um certo alastramento geográfico da pobreza, que já chegou a ser chamado de "diminuição perversa da segregação socioespacial" (Rolnik et al., 1990, p. 53-58) ou de um novo padrão de relações entre riqueza e pobreza em áreas mais periféricas, que explicaria em parte a configuração dos "enclaves fortificados" (Caldeira, 2000). Ao mesmo tempo, em áreas mais longínquas e limítrofes, registra-se a formação de novas frentes de expansão periférica já denominadas "hiperperiferias", marcadas a princípio por maior grau de precariedade que as "antigas", devido a uma combinação entre o desemprego estrutural, a crise de organização dos movimentos sociais e o abandono do Estado. ${ }^{36}$

Ainda que o quadro de organização política em torno de comunidades locais passe por certo declínio, ao menos quanto às suas características mais tradicionais, há que se pensar num novo cenário de mobilizações dentro de um panorama marcado, como já vimos, pela diminuição 
Revista de Antropologia, São Paulo, USP, 2005, v. 48 No 1.

da hegemonia das Comunidades Eclesiais de Base - que ampararam politicamente muitos desses movimentos nas décadas de 1970 e $1980^{37}$ -, bem como pela emergência de novos atores sociais, como as ONGs, cujos prós e contras quanto à atuação das mesmas na mediação dos grupos populares com o Estado despertam atenção entre estudiosos. ${ }^{38}$

Tendo em vista os enfoques do presente artigo a respeito do potencial da etnografia e do modo como tais abordagens apreendem o urbano como uma dimensão significativa, bem como o tema da prática política enquanto faceta particularmente desafiante para circunscrição e interpretação, é possível também beneficiar-se da perspectiva exposta por Holston (1993), a partir da proposta de uma etnografia crítica do modernismo - no caso, do planejamento modernista de Brasília. Nesse estudo, o autor buscou incorporar práticas cotidianas inscritas em processos históricos mais amplos por meio de um outro enquadramento teórico, levando em conta a idéia central de que se a utopia modernista - formulada por Le Corbusier e pelos manifestos do CIAM (Congrès Internationaux d'Architecture Moderne) - de conceber uma cidade inovadora em sua totalidade tinha uma visão des-historicizante, sua concretização histórica (por meio da construção de Brasília, inspirada no modelo do CIAM) levou a uma negação de tal utopia. Isso foi desempenhado tanto por operários que a construíram (com a permanência posterior nas "cidades satélites" periféricas), bem como, num outro plano, por seus novos moradores, que subverteram muitos dos usos previstos, num processo que só pôde ser reconstituído por uma etnografia voltada à historicização do presente (etnográfico), que Holston denomina etnografia crítica do modernismo (p. 16). ${ }^{39}$

Tal perspectiva propicia um approach sistemático de outros contextos (Holston, 1996), para além da "cidade modernista", incluindo análises antropológicas mais detidas dos papéis circunscritos do urbanismo e dos urbanistas numa série de intervenções nas comunidades margina- 
Heitor Frúgoli Jr. O urbano em questão na antropologia...

lizadas - e não apenas daqueles ligados ao Estado, mas também dos que atuam de distintos modos junto às camadas populares, em que o desempenho na esfera política muitas vezes sobrepuja eventuais projetos urbanísticos resultantes de tal relação. ${ }^{40}$ Além disso, abrem-se novas possibilidades de análise sobre os "contradiscursos" de inúmeros atores sociais rejeitados de forma recorrente pelo planejamento urbano. ${ }^{41}$

Retomando e avançando nesse panorama mais recente, um dado novo com relação aos anos 80 , no contexto paulistano, diz respeito ao aumento considerável do tráfico de drogas, principalmente quanto à sua atuação em áreas mais vulneráveis, demarcando-se um conjunto tenso de relações de tais grupos com os moradores (bem como com associações comunitárias, escolas etc.) (Kowarick, 2004), o que, em parte, condiciona o aumento da violência urbana nesses espaços, num fenômeno que retoma, com peculiaridades, um processo há décadas em curso em muitas favelas cariocas e já estudado em profundidade por autores como Zaluar (1985).

O conhecimento já acumulado pela antropologia sobre o tema da violência permite que se possa adentrar nessa esfera com maior consistência, não cabendo retomar tópicos já discutidos na vasta produção a respeito. Pesquisas recentes na sociologia já apontam a violência como um dado rotineiro em várias áreas periféricas de São Paulo, ${ }^{42}$ sendo que o contato de pesquisadores com habitantes de áreas periféricas ou de favelas tem implicado um conjunto de mediaçóes e procedimentos cotidianos especiais, até no modo de interpelar os entrevistados quanto a temas "delicados". 43

Outro dado mais recente, no caso de São Paulo, refere-se aos movimentos culturais realizados por grupos juvenis ligados ao hip hop, que vêm redimensionando tanto suas identidades étnicas quanto as representações sobre o próprio contexto onde vivem. Estas podem, a princípio, ser entendidas, do ponto de vista antropológico, como versóes par- 
Revista de Antropologia, São Paulo, USP, 2005, v. 48 no 1.

ticulares de categorias nativas que, uma vez refeitas esteticamente e divulgadas por meio da música, vêm ampliando certas narrativas a respeito da periferia (Guasco, 2001), o que constitui um novo campo para abordagens, exigindo, ao mesmo tempo, distanciamento de um certo fascínio que provocam. Num exame mais detido, muitas representações exacerbam a existência da violência em tais espaços por meio de aproximações e analogias com o tema do gueto, de forte tradição norte-americana, o que exige mediações na análise. ${ }^{44}$

Retomando um tema já abordado e no espírito da busca de diálogos profícuos com outras áreas, é a oportunidade de se incorporar argumentos de Wacquant, sociólogo que, a partir de ampla pesquisa etnográfica sobre um gueto negro de Chicago (1996), ${ }^{45}$ propôs uma concepção institucionalista do gueto enquanto conceito, que envolveria uma formação étnico-racial objetivamente inscrita no espaço, com uma população negativamente tipificada e o desenvolvimento de "instituições paralelas", opondo-se claramente às visões de desorganização atribuída aos mesmos ${ }^{46}$ e ressaltando seus princípios constitutivos em meio a diversas coaçôes estruturais, com a existência de uma racionalidade social local e regular. ${ }^{47}$

Tendo em vista tal densidade sociológica, Wacquant (2001) voltouse à análise de outros contextos marcados por certas formas de marginalidade e segregação socioespacial, como no caso de um banlieue parisiense - La Courneuve -, com traços socioculturais que aparentemente o aproximariam dos guetos norte-americanos, ${ }^{48}$ mas cuja comparação criteriosa demonstra que, apesar do agravamento das condiçóes de vida local, a (des)qualificação de gueto a tal espaço seria explicada em boa parte pela articulação entre discursos de uma determinada imprensa interessada em abordagens catastróficas para aumento das tiragens, de agentes públicos ou de ONGs empenhados em acirrar uma visão dramática sobre tais locais - em busca de prioridade para programas (incluindo negociações clientelistas) ou captação de recursos - e, por fim, 
Heitor Frúgoli Jr. O urbano em questão na antropologia...

de pesquisadores ou intelectuais, que, segundo o autor, equivocadamente incorporam uma metáfora como conceito na análise de tais contextos (p. 131-35).

Retornando ao enfoque da periferia, atenção especial deve ser dada ao fato de que, de um modo geral, os rappers procuram, por meio da articulação de elaborações estéticas (que se valem de questões étnicas, de gênero, geracionais e morais, entre outras), articular uma espécie de "singularização da periferia" ${ }^{49}$ - cuja novidade consiste na produção e divulgação de uma representação local ou nativa, e não de "fora para dentro". A abordagem antropológica, entretanto, deve enfocar tal fenômeno tendo em vista as distinções relevantes entre gueto e periferia (ou favela), bem como a "diversidade da periferia", tanto no plano urbanístico propriamente dito, quanto com relação ao conjunto de fenômenos socioculturais que nela se observam. Cabe assim diferenciar, no plano analítico, a periferia como área urbana específica e sujeita a distintos graus de segregação (ou, num sentido inverso, de consolidação), como fenômeno social (que, nas últimas décadas, tem envolvido um projeto familiar e comunitário de inserção na cidade, mas com certas rupturas introduzidas por diversos fatores), como um conjunto polifônico de representações nativas (cujas predominâncias tipológicas cabe definir caso a caso), bem como uma série de narrativas, das quais se destaca a realizada por atores sociais como os rappers.

Para concluir, espero ter auxiliado na delimitação de temas para a configuração de um campo voltado a uma antropologia da cidade, não tanto no sentido de uma autonomização da esfera urbana com relação a outras dimensões determinantes, mas principalmente quanto a abordagens nas quais, como já se disse, tal dimensão seja alvo de um esforço especial e sistemático de reflexão. Isso implica não só recuperar como buscar se beneficiar das reflexôes e dos debates já acumulados, incluindo a possível utilização renovada de certos conceitos, com clara atenção 
a uma certa genealogia dos mesmos, ${ }^{50}$ para que não se perca sua capacidade interpretativa.

Ao frisar como os períodos enfocados evidenciam diálogos nos quais as disciplinas envolvidas passam por mudanças substanciais, procuro evitar qualquer perspectiva "evolucionista" quanto à dinâmica de tal interlocução, embora, como vimos, os objetos ou fenômenos enfocados tenham, ao menos nos recortes propostos no artigo, uma certa continuidade temática.

As interlocuções da antropologia com a sociologia em torno da cidade revelam-se nesse sentido um campo fértil, contanto que com claras mediaçóes e com vistas a proporcionar, ao mesmo tempo, uma crescente autonomia à esfera antropológica.

A dinâmica de tais interfaces não depende, entretanto, apenas de lógicas presentes no campo intelectual e acadêmico, mas de fenômenos urbanos relevantes que exijam interpretações e análises. E em momentos de intensificação dessas interlocuções, a prática etnográfica ${ }^{51}$ tem se revelado, como vimos, um dado diferencial bastante significativo, cabendo continuar a explorar ou mesmo a radicalizar seu potencial, com atenção especial às múltiplas formas com que emergem e se entrelaçam, nos contextos pesquisados, os temas da política - dimensão crucial em vários grupos sociais a partir dos anos 80 - e da cultura - termo que hoje se multiplica pelos usos abusivos do conceito ${ }^{52}$ ou por meio da prática de inúmeros grupos que se apresentam na cena pública como portadores de culturas específicas.

\section{Notas}

1 O presente artigo sintetiza temas que venho elaborando em minha trajetória acadêmica mais recente. Agradeço especialmente aos comentários, quando da discussão 
Heitor Frúgoli Jr. O urbano em questão na antropologia...

de certos temas aqui tratados, dos participantes de um grupo de estudo que organizei a partir do início de 2005, formado por meus orientandos Daniel De Lucca Reis Costa, Jessica Sklair Corrêa, Sidnei Ferreira Duarte e Daniel Maciel, além de Paula Morgado Dias Lopes, Caroline Hilário Macedo, Pedro Guasco, Anna Catarina Morawska Viana, Carlos Aquino, Cláudio Fernando Arrighi Czarnobai e Joana Benetton; sou também grato a Fernanda Peixoto, Fraya Frehse, Lilia Schwarcz, Luiz Henrique de Toledo, Marta Amoroso, Piero Leirner e André Setti; aos amigos e colegas da revista Sexta-Feira; aos alunos do meu curso "Espaço urbano, segregação e urbanismo na perspectiva antropológica" (10 semestre de 2005); por fim, ao parecerista anônimo da Revista de Antropologia, pelos tópicos assinalados.

2 Ver a abordagem de tal tema, de longa data na antropologia urbana, em Durham (2004[1986a], p. 361-62), visto como a tentativa da compreensão do fenômeno urbano em si mesmo, e em Magnani (2002, p. 24-25), com relação à busca de princípios mais abrangentes ou de estruturas de longa duração.

3 Tento tornar mais preciso um campo muito amplo e abrangente, no qual a dimensão urbana propriamente dita pode ter um caráter apenas secundário ou residual. Um exemplo, entre outros, é o panorama proposto por Montero (2004, p. 13638), mapeando linhas de pesquisa no Brasil que caracterizariam uma "antropologia das formas urbanas" - que a própria autora admite comportar temáticas muito diversificadas (p. 125) -, abarcando temas como meio ambiente, comunicaçáo, arte e cultura, consumo, educação, esporte, entre outros, que, na presente perspectiva, não seriam a priori temas da antropologia urbana, embora possam vir a sê-lo a partir de certos enquadramentos.

4 Apesar da forte influência da Escola de Chicago, reconheço evidentemente que o campo da antropologia urbana é mais amplo em sua formação se o pensarmos, como mostra Hannerz (1980, p. 119-62) quanto aos estudos da Escola de Manchester na África entre os anos 1940-1950, também centrado no tema da mudança social, mas do ponto de vista estrutural-funcionalista, voltado a cidades que vinham passando por um rápido crescimento, com membros de grupos tribais que também se tornavam operários de minas, com mudanças identitárias abordadas da ótica da "tribalização-destribalização" no contexto urbano (tendo como pano de fundo a polaridade clássica da antropologia entre sociedades tribais e não tribais ou modernas, distinta da polaridade rural-urbano que predominou na antropolo- 
gia urbana ligada a Chicago), dentre seus desdobramentos na Inglaterra, pode-se mencionar os estudos de Cohen sobre etnicidade urbana (1980). Para um outro breve panorama sobre as primeiras etnografias urbanas, com destaque para a centralidade da Escola de Chicago, ver Sanjek (2002, p. 555-56).

5 Becker (1996, p. 179) vê a Escola de Chicago mais como uma "escola de atividade", na qual se trabalhava em conjunto, sem que necessariamente se compartilhasse a mesma teoria, tal como ocorre numa "escola de pensamento".

6 Joseph (cf. Valladares \& Kant de Lima, 2000) aborda tal retomada com base em fenômenos ligados a interações entre distintos grupos étnicos no espaço urbano francês, com dilemas ligados a um multiculturalismo que parece "aportar" naquele contexto, embora tal configuração não seja suficiente para explicar a recuperação dessa escola. Isso também passa pela releitura e revisão de certos conceitos, voltadas a uma melhor compreensão sociológica (ou "microssociológica") da dimensão urbana e do sentido das interações nos espaços públicos - para mais detalhes, ver Joseph (2000).

7 Sobre tal interface, ver Schwarcz (2000); sobre uma antropologia do passado urbano, nos diálogos com a história e a sociologia, ver Frehse (2005).

8 É impossível dar conta da magnitude de tal interface, bastando mencionar, por exemplo, como toda uma vertente da antropologia francesa dialoga com a obra de Durkheim, notadamente sua produção mais tardia sobre religião; com RadcliffeBrown, houve uma forte aproximação da antropologia funcional-estruturalista com a sociologia; numa vertente mais contemporânea, é muito significativa a influência de Bourdieu em inúmeras abordagens antropológicas.

9 Peirano (1995, p. 44) nos lembra de que "Evans-Pritchard (1972) dizia não haver 'fatos sociais' na antropologia, mas 'fatos etnográficos'.

10 Para mais detalhes sobre essa questão, ver Hannerz (1980, p. 19-58). Isso também aponta uma certa visão sobre uma polêmica "divisão de trabalho" entre as mesmas, ficando a cargo da sociologia a "macroteoria" e da antropologia apenas os "métodos de pesquisa empírica qualitativa". Em artigo recente, Stocking (2004) assinala que na Universidade de Chicago o Departamento de Sociologia e Antropologia (com ampla hegemonia da primeira) foi fundado em 1892, e o de Antropologia apenas em 1929. De modo geral, estudantes com vocação antropológica, mas com certo interesse na atmosfera urbana de Chicago - marcada pela variedade étnica, riqueza cultural, solidão anômica e corrupção -, acabavam por envere- 
Heitor Frúgoli Jr. O urbano em questão na antropologia...

dar pela sociologia. Tal atmosfera de marginalidade cultural da antropologia veio a ser parcialmente interrompida a partir dos estudos de Redfield, que estabeleceu um novo plano de diálogo entre a antropologia cultural e a sociologia.

11 Para uma retomada crítica a respeito, ver Frúgoli Jr. (2003, p. 108-11).

12 Combinação que também pode ser lida em Simmel, segundo Waizbort (2000, p. 333), por meio da relação ambígua entre proximidade corporal e distância espiritual.

13 Outro tema ainda seria a secularização resultante da urbanização, elaborada por autores como Redfield (conferir mais detalhes em Oliven, 1985, p. 41-45).

14 Como aponta Eufrasio (1999, p. 276-77 e 287), a interpretação ecológica esteve presente apenas na gênese da teoria da estrutura urbana da Escola de Chicago, sendo falacioso repudiar esta última e alijar a dimensão espacial da investigação sociológica, com base num suposto vínculo intrínseco entre o estudo da organização espacial da cidade e a interpretação ecológica. Numa outra linha de argumentação, Joseph (cf. Valladares \& Kant de Lima, 2000, p. 6-7) pondera que o tema da ecologia, pela Escola de Chicago, teria sido polêmico num bom sentido, como resposta a uma certa literatura eugenista e antiurbana da época, frisando que a cidade não seria apenas um mosaico de territórios, mas as relações entre duas ou mais populaçôes num mesmo meio ou sistema de atividades, presentes em fenômenos como a economia da mobilidade residencial, problemas sociais de co-habitação residencial ou de co-presença no espaço público.

15 Como ressalta Eufrasio (1999, p. 186), os resultados de tais abordagens empíricas terminavam por colidir com as próprias concepções teórico-conceituais ecológicas, sobretudo quanto ao ponto de vista mais geral de uma "organização espacial da cidade como resultado de processos não-sociais, impessoais e inconscientes de competição e luta pelo sustento".

16 No original, hobo.

17 O que incluía espécies de "conversōes" diante da necessidade de obter abrigo temporário de instituiçôes religiosas (Hannerz, 1980, p. 34).

18 O enclave seria definido, segundo Marcuse (1997), com base num caráter étnico voluntário de segregação, ao contrário dos guetos propriamente ditos, que teriam uma formação involuntária, e assim seriam fundamentalmente atribuídos a áreas ocupadas por negros pobres em várias cidades norte-americanas. A pesquisa etnográfica pioneira sobre negros nos Estados Unidos, anterior à Escola de Chicago, foi realizada por Dubois (1899) na Filadélfia. 
19 Literalmente, "dinâmica de pequenos grupos".

20 Para aproximaçóes e distâncias entre os conceitos de gangues (no contexto norteamericano) e quadrilhas (no contexto brasileiro, mais precisamente, carioca), ver Zaluar (1997).

21 Assim, parte da crítica antropológica à Escola de Chicago também se consolidou quando dos trabalhos de Lewis sobre Tepoztlán (1951) - revendo criticamente o trabalho etnográfico anterior de Redfield na mesma aldeia (1974[1930]) - e depois em sua pesquisa com migrantes do campo na Cidade do México (1976 [1965]), o que possibilitou um conjunto de críticas articuladas ao continuum folkurbano - que trazia em si uma visão mais homogênea do contexto urbano, sem marcas de uma tradição de fundo rural. Para mais detalhes, ver Frúgoli Jr. (2003, p. 110-11).

22 Embora importante, não abordarei neste artigo outro período profícuo de interlocução e colaboração entre antropologia e sociologia, entre os anos 40 e 50, centrado nos estudos de comunidade, introduzidos em São Paulo por Donald Pierson na Escola de Sociologia Política e por Emílio Willems na Universidade de São Paulo, momento em que ambas as disciplinas "estavam muito próximas, movendo-se dentro de tendências teóricas e metodológicas que se superpunham" (Durham, 2004, p. 22). Para uma reconstituição das colaborações entre tais disciplinas nesse período, em seus respectivos nichos institucionais, ver Peixoto e Simões (2003). Reconheço também que no Rio de Janeiro tal diálogo entre essas disciplinas ganhou outras sínteses, sendo que nesse caso o tema da favela foi (e continua sendo) a principal forma de segregação socioespacial em termos de enfoque (Zaluar \& Alvito, 1998) e de interlocução entre inúmeras áreas do saber (Valladares \& Medeiros, 2003).

23 Com destaque inicial para Castells (1983[1972]). Para um amplo quadro a respeito, ver Véras (2000).

24 Lewis, já mencionado neste artigo, foi bastante criticado por uma abordagem excessivamente culturalista a respeito da "cultura da pobreza" (1966).

25 Para um panorama a respeito, ver Kowarick (1997), lembrando que várias reflexões em curso sobre redemocratização e cidadania passavam bastante pelo crivo desses enfoques. O presente artigo não pretende abranger, evidentemente, outras linhas no interior do marxismo voltadas à dimensão urbana, cabendo, no entanto, destacar Lefebvre (1969), cujo trabalho criou bases para pesquisas ligadas a 
Heitor Frúgoli Jr. O urbano em questão na antropologia...

uma sociologia da vida cotidiana, tal como nas abordagens de Martins (1992), em que o lócus privilegiado de análise é o subúrbio. No contexto carioca, pode-se salientar Leeds \& Leeds (1978), quanto a uma antropologia norte-americana que buscou dialogar significativamente com a questão das classes sociais e do Estado, baseada em trabalhos de campo em favelas cariocas e com grupos de baixa renda em áreas marginalizadas de outras cidades latino-americanas.

26 Há um interessante panorama a respeito num depoimento de Nabil Bonduki (Leme et al., 2001), relatando um campo de experiências de intervenção com base na autogestão, em áreas periféricas paulistanas; no campo do próprio urbanismo, para uma reflexão abrangente sobre as relações de "arquitetos de esquerda" com as classes populares no campo das açôes ligadas aos mutirões, ver Arantes (2002). No Rio de Janeiro, por sua vez, pode-se mencionar uma instigante interlocução entre o planejamento urbano voltado às favelas e a antropologia na abordagem de Santos (1980).

27 No Rio de Janeiro, os trabalhos de Gilberto Velho dialogam bastante com temas da Escola de Chicago - para um quadro sintético, ver Velho (1999) -, além de uma aproximação mais significativa com a obra de Louis Dumont, bem mais presente no contexto carioca que no paulista. A obra de DaMatta a partir de Carnavais, malandros e heróis (1980) tem também forte ressonância na antropologia urbana, embora possa ser situada, mais precisamente, no campo de uma "antropologia da sociedade nacional” (ver argumentos em Gomes, Barbosa e Drummond, 2000).

28 Vários trabalhos dessa época sobre tal temática foram orientados por Eunice Durham ou por Ruth Cardoso.

29 Para mais detalhes sobre tal polaridade, ver Durham (2004[1984]). No campo da sociologia, uma instigante reflexão sobre classes populares, buscando abarcar uma heterogeneidade de agentes e práticas, foi realizada por Paoli \& Sáder (1986).

30 Fenômeno que no contexto carioca - mais próximo, como já foi dito, das referências dumontianas - foi lido à luz do conceito de cidadanização, pensada como uma espécie de conversão das classes populares, imersas no universo hierárquico, ao universo igualitário (cf. Duarte et al., 1993).

31 A autora referia-se tanto a soluções decorrentes da adoção de etnografias de inspiração funcionalista com interpretações que buscavam se aproximar de conceitos de cunho marxista (anteriores e exteriores à reflexão) ou, pela via estruturalista 
(que tenderia a sacrificar as particularidades), através da utilização de conceitos do culturalismo que, voltados à interpretação de realidades distintas daquelas as quais originalmente se referiam, se tornavam então apenas alusivos ou metafóricos, quando não redutores ou antagônicos.

32 Deixo claro o reconhecimento que tal campo de produção antropológica bem como de interlocuçôes se expandiu consideravelmente em todo o Brasil. No caso específico deste artigo, estarei pensando novamente o caso de São Paulo, onde de certo modo se pode falar de uma espécie de enfraquecimento desse diálogo.

33 Foi o que observei ao orientar algumas pesquisas sobre cidades médias do interior paulista quando fui professor da UNESP de Araraquara; várias delas voltadas a áreas periféricas, cuja paisagem se distancia do caso paulistano, mas não determinados fenômenos socioculturais em curso.

34 Fica para um outro artigo uma abordagem mais detida sobre os temas de centro, centralidade, interações no espaço público e gentrification.

35 Dentre os trabalhos que enfocam relações entre consolidação de áreas mais periféricas e esvaziamento do ponto de vista da ocupação residencial, com ênfase no caso da zona leste paulistana, ver Rolnik \& Frúgoli Jr. (2001).

36 Dentre os estudos dedicados ao tema, ver Torres \& Marques (2001).

37 Um dado bastante relevante diz respeito ao modo como, em tais contextos, têm incidido os processos de conversão popular às religiōes evangélicas e pentecostais, com mudanças nos hábitos cotidianos, nas relaçôes de sociabilidade e até nos modos de produzir relacionamentos comunitários. Dentre os inúmeros trabalhos a respeito, ver Alvito (2001), quanto às favelas cariocas.

38 Sobre a relação de ONGs com movimentos populares, ver pesquisa em curso de Rizek \& Barros (2004).

39 Crítica, no caso, em relação ao contexto sociocultural mais amplo contemplado, e não quanto aos objetos etnográficos mais detidamente analisados, o que poderia induzir equivocadamente a uma visão apriorística sobre os grupos pesquisados.

40 Ver discussão a respeito na já mencionada entrevista com Nabil Bonduki (Leme et al., 2001).

41 Um dos desdobramentos da etnografia crítica do modernismo seria, nesse sentido, "planejar o etnograficamente possível", numa aproximação específica entre a prática arquitetônica e o fazer etnográfico (Holston, 1996, p. 252-53). 
Heitor Frúgoli Jr. O urbano em questão na antropologia...

42 Enquanto um aspecto constitutivo mais recente da esfera do "cidadão privado" (Kowarick, 2004), cabendo aos habitantes saber aonde ir e não ir, bem como os horários permitidos ou não para certas práticas, forjando determinados comportamentos defensivos (p. 111-18).

43 Tais como a presença da bandidagem, assassinato de parentes, desemprego etc. (Kowarick, 2004, p. 11). No Rio de Janeiro, a dimensão da violência teria hoje, segundo Gilberto Velho, a capacidade de interferir mesmo em pesquisas não voltadas ao tema, enquanto risco a ser constantemente avaliado na prática do trabalho de campo, ou mesmo como tópico de reflexão mais sistemática (cf. palestra no simpósio "Antropologia urbana: problemas, questôes e perspectivas", $23^{a}$ Reunião Brasileira de Antropologia da ABA, 18/6/2002).

44 Pesquisa mais recente de Teresa Caldeira, ainda não publicada, aborda o universo do hip hop e suas articulaçôes simbólicas com o tema do gueto.

45 Pesquisa durante a qual uma das estratégias etnográficas foi ele mesmo tornar-se boxeador de uma academia no interior do gueto (Wacquant, 2002), com prós ligados à possibilidade de adentrar num mundo de regras que iluminam por inversão o contexto local do bairro - e contras - ligados sobretudo a uma prática próxima de "participação observante" - que não serão aqui explorados.

46 Noção, como já vimos, bastante enraizada no imaginário norte-americano.

47 Visível a partir do rompimento de visóes marcadas pelo exotismo - ainda que se possa indagar sobre o perigo de um excessivo relativismo de tal crítica.

48 Como o aumento da violência urbana, da deterioração dos conjuntos habitacionais, do desemprego e do racismo (dirigido a grupos de imigrantes africanos que vêm habitando tais áreas) (Wacquant, 2001, p. 129-35).

49 Como mostra Guasco (2001, p. 141-42), a visão construída pelos rappers sobre a periferia tende a acentuar sua faceta de pobreza e violência, dividindo a sociedade em dois mundos, tornando-se, no plano das representações, uma categoria relacional (agradeço aos comentários de Luiz Henrique de Toledo, quando da minha apresentação da palestra Periferia(s) da cidade de São Paulo: diálogos entre antropologia e sociologia na "Semana de Ciências Sociais da Universidade Federal de São Carlos”, em 17/5/2005).

50 Apenas para exemplificar: é bastante oportuno mapearmos como o conceito de sociabilidade, amplamente utilizado nas pesquisas antropológicas, foi originalmente proposto pela filosofia social de Simmel (Waizbort, 2000), ressignificou-se atra- 
vés da Escola de Chicago ao ganhar uma determinada territorialidade (Eufrasio, 1996) e ganhou outras releituras da antropologia urbana contemporânea - tal como a que utilizei em minha pesquisa sobre os shopping centers, a fim de compreender um conjunto específico de interações sociais num espaço de acesso público (Frúgoli Jr., 1992). Dada a amplitude de tal uso, pode ser importante, na construção de objetos de pesquisa, situar determinadas filiações específicas ao conceito.

51 Que na medida em que vem sendo incorporada por outras disciplinas, mereceria reflexôes quanto aos significados, já que em muitos casos parece se confundir com a realização de entrevistas.

52 Num artigo sobre a obra de Eunice Durham, apresentado no "XXVIII Encontro da Anpocs" (2004), Alba Zaluar (2005, p. 204) chama a atenção, na realidade contemporânea, para o uso abusivo do conceito de cultura para qualificar comportamentos ou imaginários ou aspectos conjunturais, como se fossem sistemas únicos, circunscritos e autônomos.

\section{Bibliografia}

ALTHUSSER, L.

1974

Ideologia e aparelhos ideológicos de Estado, Lisboa, Presença.

ALVITO, M.

2001 As cores de Acari: uma favela carioca, Rio de Janeiro, FGV.

ANDERSON, N.

1961[1923] The hobo, Chicago, University of Chicago Press.

ARANTES, P. A.

2002

Arquitetura nova: Sérgio Ferro, Flávio Império e Rodrigo Lefêre, de Artigas aos mutirōes, São Paulo, Ed. 34.

BECKER, $\mathrm{H}$.

1996 "Conferência: a escola de Chicago", Mana - Estudos de Antropologia Social, Rio de Janeiro, vol. 2(2): 177-88. 
Heitor Frúgoli Jr. O urbano em questão na antropologia...

CALDEIRA, T. P. R.

1984

A politica dos outros: o cotidiano dos moradores da periferia e o que pensam do poder e dos poderosos, São Paulo, Brasiliense.

2000 Cidade de muros: crime, segregação e cidadania em São Paulo, São Paulo, Edusp/ Ed. 34 .

CASTELLS, M.

1983[1972] A questão urbana, Rio de Janeiro, Paz e Terra.

COHEN, A.

1980

"Drama and politics in the development of a London carnival", Man - The Journal of The Royal Anthropological Institute, London, vol. 15(1): 65-87.

CUIN, C. \& GRESLE, F.

1994

História da sociologia, São Paulo, Ensaio (Cadernos Ensaio Pequeno Formato, 10).

DAMATTA, R.

1980 Carnavais, malandros e heróis: para uma sociologia do dilema brasileiro, Rio de Janeiro, Jorge Zahar.

DUARTE, L. F.; BARSTED, L. L.; TAULOIS, M. R. \& GARCIA, M. H.

1993

"Vicissitudes e limites da conversão à cidadania nas classes populares brasileiras", Revista Brasileira de Ciências Sociais, vol. 8(22): 5-19.

DUBOIS, W. E. B.

The Philapelphia Negro, Philadelphia, University of Philadelphia Press.

DURHAM, E. R.

2004[1984] "Cultura e ideologia", in DURHAM, E. R., A dinâmica da cultura, São Paulo, Cosac \& Naify, p. 259-79.

2004 [1986a] "A pesquisa antropológica com populações urbanas", in DURHAM, E. R., $A$ dinâmica da cultura, São Paulo, Cosac \& Naify, p. 357-76.

2004[1986b] "A sociedade vista da periferia", in DURHAM, E. R., A dinâmica da cultura, São Paulo, Cosac \& Naify, p. 377-407.

2004 "Introdução", in DURHAM, E. R., A dinâmica da cultura, São Paulo, Cosac \& Naify, p. 19-51. 


\section{EUFRASIO, M. A.}

1996 "A temática da sociabilidade na Escola Sociológica de Chicago", Sociabilidades - Laboratório de Análises da Sociabilidade Contemporânea, São Paulo, 1: 37-44.

1999 Estrutura urbana e ecologia humana: a Escola Sociológica de Chicago (1915-1940), São Paulo, PPGS-USP/Ed. 34.

EVANS-PRITCHARD, E. E.

1972 Antropologia social, Lisboa, Ed. 70.

FREHSE, F.

2005 O tempo das ruas na São Paulo de fins do Império, São Paulo, Edusp.

FRÚGOLI JR., H.

1992 "Os shoppings de São Paulo e a trama do urbano: um olhar antropológico", in PINTAUDI, S. M. \& FRÚGOLI JR., H. (orgs.), Shopping centers: espaço, cultura e modernidade nas cidades brasileiras, São Paulo, Ed. da Unesp, p. 75-92.

2003 "A dissolução e a reinvenção do sentido de comunidade em Beuningen, Holanda”, Revista Brasileira de Ciências Sociais, São Paulo/Bauru, vol. 18(52): 109-26.

GOLDMAN, M.

1999[1995] "Antropologia contemporânea, sociedades complexas e outras questões", in GOLDMAN, M., Alguma antropologia, Rio de Janeiro, Relume Dumará, p. 93-122.

GOMES, L. G.; BARBOSA, L. \& DRUMMOND, J. A. (orgs.)

2000 O Brasil não é para principiantes: carnavais, malandros e heróis, 20 anos depois, Rio de Janeiro, FGV.

GUASCO, P. P. M.

2001 "Num país chamado periferia: identidade e representação da realidade entre os

"rappers" de São Paulo", São Paulo, 165 pp., dissertação de mestrado, PPGAS, USP.

HANNERZ, U.

1980

Exploring the city: inquiries toward an urban anthropology, New York, Columbia University Press. 
Heitor Frúgoli Jr. O urbano em questão na antropologia...

HOLSTON, J.

1993 A cidade modernista: uma crítica de Brasilia e sua utopia, São Paulo, Companhia das Letras.

1996 "Espaços de cidadania insurgente", Revista do Patrimônio Histórico e Artístico Nacional, Rio de Janeiro, 24: 243-53.

JOSEPH, I.

2000 Erving Goffman e a microssociologia, Rio de Janeiro, FGV.

KOWARICK, L.

1979 A espoliação urbana, Rio de Janeiro, Paz e Terra.

1997 "Espoliação urbana, lutas sociais e cidadania: fatias de nossa história recente", Espaço \& Debates, São Paulo, ano XII, 40: 105-13.

2000 Escritos urbanos, São Paulo, Ed. 34.

2004 Vulnerabilidade socioeconômica e civil em bairros populares: sociologia \& história \& etnografia, datilo.

LEEDS, A. \& LEEDS E. R.

1978 A sociologia do Brasil urbano, Rio de Janeiro, Zahar.

LEFEBVRE, $\mathrm{H}$.

1969 O direito à cidade, São Paulo, Documentos.

LEME, M. C. S.; CYMBALISTA, R. \& FELDMAN, S.

2001 "Depoimento - Nabil Bonduki”, Espaço \& Debates, São Paulo, XVII(42): 92-99.

LEWIS, O.

1951 Life in a Mexican village: Tepoztlán restudied, Urbana, University of Illinois Press.

1966 "The culture of poverty", Scientific American, vol. 215, n. 4.

1976[1965] "Outras observações sobre o continuum folk-urbano com referência à Cidade do México", in HAUSER, P. M. \& SCHNORE, L. F. (orgs.), Estudos de urbanização, São Paulo, Livraria Pioneira, p. 461-72.

MACEDO, C. C.

1979 A reprodução da desigualdade, São Paulo, Hucitec. 


\section{Revista de Antropologia, São Paulo, USP, 2005, v. 48 no 1.}

MAGNANI, J. G. C.

1984

Festa no pedaço: cultura popular e lazer na cidade, São Paulo, Brasiliense.

2002

"De perto e de dentro: notas para uma etnografia urbana", Revista Brasileira de Ciências Sociais, vol. 17(49): 11-29.

MARCUSE, P.

"The enclave, the citadel, and the ghetto: what has changed in the post-fordist U.S. city", Urban Affairs Review, St. Louis, vol. 33(2): 228-64.

MARQUES, E. C. \& BICHIR, R. M.

2001 "Investimentos públicos, infra-estrutura urbana e produção da periferia em São Paulo”, Espaço \& Debates, ano XVII, 42: 9-30.

MARTINS, J. S.

Subúrbio - Vida cotidiana e história no subúrbio da cidade de São Paulo: São Caetano, do fim do Império ao fim da República Velha, São Paulo/São Caetano do Sul, Hucitec/Prefeitura de São Caetano do Sul.

MONTERO, P.

2004

"Antropologia no Brasil: tendências e debates", in TRAJANO FILHO, W. \& RIBEIRO, G. L. (orgs.), O campo da antropologia no Brasil, Rio de Janeiro, Contra Capa Livraria/ABA, p. 117-42.

MUSUMECI, L.

"Totens e tabus nas relações Antropologia/Psicanálise, ou o sentido de um retorno a Malinowski”, Dados - Revista de Ciências Sociais, vol. 34(2): 219-48.

OLIVEN, R. G.

1985 A antropologia de grupos urbanos, Petrópolis, Vozes.

PAOLI, M. C. \& SÁDER, E.

1986 "Sobre 'classes populares' no pensamento sociológico brasileiro (notas de leitura sobre acontecimentos recentes)", in CARDOSO, R. (org.), A aventura antropológica. Teoria e pesquisa, Rio de Janeiro, Paz e Terra, p. 39-67. 
Heitor Frúgoli Jr. O urbano em questão na antropologia...

PARK, R. E.

1987[1916] "A cidade: sugestōes para a investigação do comportamento humano no meio urbano", in VELHO, O. G. (org.), O fenômeno urbano, Rio de Janeiro, Ed. Guanabara, p. 26-67.

PEIRANO, M.

1995 A favor da etnografia, Rio de Janeiro, Relume-Dumará.

PEIXOTO, F. A. \& SIMÕES, J. A.

2003 "A Revista de Antropologia e as ciências sociais em São Paulo: notas sobre uma cena e alguns debates", Revista de Antropologia, vol. 46(2): 383-409.

REDFIELD, R.

1947 "The folk society", American Journal of Sociology, vol. 52, n. 4.

1974[1930] Tepoztlan: a mexican village - A study of folk life, Chicago/London, The University of Chicago Press.

RIZEK, C. S. \& BARROS, J. S.

2004 "Mutirōes autogeridos: construção e desconstrução de sociabilidades", paper para a XXIV Reunião Brasileira de Antropologia, Associação Brasileira de Antropologia, Olinda, datilo.

ROLNIK, R. \& FRÚGOLI JR., H.

2001 "Reestruturação urbana da metrópole paulistana: a Zona Leste como território de rupturas e permanências”, Cadernos Metrópole, São Paulo, 6: 55-83.

ROLNIK, R.; KOWARICK, L. \& SOMEKH, N. (coord.)

1990 São Paulo: crise e mudança, São Paulo, Brasiliense/SEMPLA.

SANJEK, R.

2002

"Urban anthropology", in BARNARD, A. \& SPENCER, J. (ed.), Encyclopedia of social and cultural anthropology, London/New York, Routledge, p. 555-58.

SANTOS, C. N. F.

1980

"Como e quando pode um antropólogo virar arquiteto?", in VELHO, G. (org.), $O$ desafio da cidade, Rio de Janeiro, Campus, p. 37-57. 
Revista de Antropologia, São Paulo, USP, 2005, v. 48 no 1.

SCHWARCZ, L. M.

2000 "Marshall Sahlins ou por uma antropologia estrutural e histórica”, Cadernos de Campo, 10(9): 125-33.

SIMMEL, G.

1983[1917] “Sociabilidade - um exemplo de sociologia pura ou formal”, in: MORAES, E. (org.), Sociologia: Simmel, São Paulo, Ática, p. 165-81.

1987[1902] "A metrópole e a vida mental", in VELHO, O. G. (org.), O fenômeno urbano, Rio de Janeiro, Guanabara, p. 11-25.

STOCKING JR., G. W.

2004 "Antropologia em Chicago: a fundação de um departamento independente 1923-1929”, in PEIXOTO, F. A.; PONTES, H. \& SCHWARCZ, L. M. (orgs.), Antropologias, histórias, experiências, Belo Horizonte, Ed. UFMG, p. 15-59.

THRASHER, F. M.

1963[1927] The gang, Chicago, University of Chicago Press.

TORRES, H. G. \& MARQUES, E. C.

2001 "Reflexões sobre a hiperperiferia: novas e velhas faces da pobreza no entorno metropolitano", Revista Brasileira de Estudos Urbanos e Regionais, 4.

VALLADARES, L. P. \& KANT DE LIMA, R.

2000 "A Escola de Chicago: entrevista com Isaac Joseph", BIB - Revista Brasileira de Informação Bibliográfica em Ciências Sociais, Rio de Janeiro, 49: 3-13.

VALLADARES, L. P. \& MEDEIROS, L.

2003 Pensando as favelas do Rio de Janeiro (1906-2000): uma bibliografia analítica, Rio de Janeiro, Relume Dumará/Faperj/Urbandata.

VELHO, G.

1999

"Os mundos de Copacabana”, in VELHO, G. (org.), Antropologia urbana: cultura e sociedade no Brasil e em Portugal, Rio de Janeiro, Jorge Zahar, p. 11-23.

VELHO, G. \& VIVEIROS DE CASTRO, E.

1978 "O conceito de cultura e o estudo de sociedades complexas: uma perspectiva antropológica”, Artefato, Rio de Janeiro, 1, jan., CEC. 
Heitor Frúgoli Jr. O urbano em questão na antropologia...

VÉRAS, M. P. B.

2000 Trocando olhares: uma introdução à construção sociológica da cidade, São Paulo, Educ/Studio Nobel.

VIVEIROS DE CASTRO, E.

2002[1996] "O conceito de sociedade em antropologia", in VIVEIROS DE CASTRO, E., A inconstância da alma selvagem, São Paulo, Cosac \& Naify, p. 295-316.

WACQUANT, L. J. D.

1996 "Três premissas perniciosas no estudo do gueto norte-americano", Mana - Estudos de Antropologia Social, vol. 2(2): 145-61.

2001 Os condenados da cidade: estudo sobre marginalidade avançada, Rio de Janeiro, Revan/Fase.

2002 Corpo e alma: notas etnográficas de um aprendiz do boxe, Rio de Janeiro, Relume Dumará.

WAIZBORT, L.

2000 As aventuras de Georg Simmel, São Paulo, Ed. 34.

WHYTE, W. F.

1943 Street corner society, Chicago, University of Chicago Press.

WIRTH, L.

1956[1928] The ghetto, Chicago, University of Chicago Press.

1987[1938] "O urbanismo como modo de vida", in VELHO, O. G. (org.), O fenômeno urbano, Rio de Janeiro, Ed. Guanabara, p. 90-113.

ZALUAR, A.

A máquina e a revolta: as organizaçôes populares e o significado da pobreza, São Paulo, Brasiliense.

1997 "Gangues, galeras e quadrilhas: globalização, juventude e violência", in VIANNA, H. (org.), Galeras cariocas, Rio de Janeiro, Ed. UFRJ, p. 17-57.

2005 "Em presença”, Novos Estudos, São Paulo, 71: 197-206.

ZALUAR, A. \& ALVITO, M. (orgs.)

1998 Um século de favela, Rio de Janeiro, FGV. 
ABSTRACT: The article deals with subjects regarding the urban sphere in anthropology by exploring dialogues between this discipline and sociology in three specific moments. The first one refers to the initial decades of the so-called Chicago School, which defined an agenda of ethnographic researches about the city and urban culture, so that there appeared the first investigations about social and spatial segregation concerned mainly with the concept of ghetto. The second one is related to the interfaces between urban anthropology and sociology in São Paulo of the decades of 1970 and 1980 regarding the issue of periphery. These researches were characterized by a polarization between the concepts of culture and ideology. At last the article focuses on present challenges to urban anthropology. One tries, on one hand, to recover topics related to a dialogue between anthropology and sociology which nowadays occurs only implicitly. On the other hand, one revisits the issue of periphery by having in mind recent phenomena that imply analyzing it simultaneously as a spatial order, a process and a polyphonic set of native representations.

KEY-WORDS: urban anthropology, urban sociology, discipline dialogues, social and spatial segregation.

\section{Aceito em setembro de 2005.}

